\title{
Interpersonal Emotion Regulation in the Workplace: A Conceptual and Operational Review and Future Research Agenda
}

\begin{abstract}
Employees need to regulate their own emotions as well as the emotions of others to enhance the quality of interactions with their colleagues. How well this is achieved has important outcomes for both employees and the organisations in which they work. In the field of organisational science, however, differing approaches have emerged regarding the conceptualisation and operationalisation of emotion regulation (ER) particularly in terms of interpersonal interactions. In the present review, we examine contemporary theoretical perspectives of ER and its measurement with a view to resolving the confusion that currently exists around interpersonal ER in a workplace context. To understand how this field of research has developed so diversely, we begin by demonstrating the influence of three major individual-level ER models on interpersonal-level approaches: (1) the ER process model; (2) emotional labor and (3) emotional intelligence. Moreover, to make sense of the range of interpersonal-level research underpinned by these theories, we present a 2 x 2 categorisation, developed by Zaki and Williams (2013), that shows how workplace researchers have variously approached interpersonal ER as an intrinsic versus extrinsic process, with activation of either response-dependent or response-independent categories. This categorisation broadly shows interpersonal ER theory utilised in work contexts tends to fall into four groupings as: (1) a purely extrinsic process, (2) a differentiation of extrinsic interpersonal from intrinsic individual ER, (3) co-occurring intrinsic and extrinsic interpersonal ER, or (4) interpersonal coregulation. We also discuss the measurement of interpersonal ER and conclude by highlighting emerging research directions.
\end{abstract}

Keywords: emotion, emotion regulation, individual level, interpersonal level 


\section{Interpersonal Emotion Regulation in the Workplace: A Conceptual and Operational Review and Future Research Agenda}

The important role of emotional regulation (ER) at work (i.e. the experience and expression of emotions determined by the activation of ER strategies, see Gross and John 2003) is today reflected in a burgeoning literature on this topic (e.g. Côté et al. 2008; Gross 2015; Lawrence et al. 2011). Although extensive research has been conducted primarily at the individual-level of analysis, researchers today (e.g. Côté et al. 2013; Kafetsios et al. 2014a, 2014b; Little et al. 2012; Niven et al. 2012a, 2012b; Zaki and Williams 2013) are beginning to recognise the critical importance of ER as an interpersonal phenomenon. In particular, evidence is emerging that employees’ perceptions of workplace events shape their emotional experiences and expressions as well as the emotional experiences and expressions of others (Grandey et al. 2013; Lawrence et al. 2011).

Researchers have found that regulating emotions at the individual-level (i.e. strategies to aid employee's regulation of their own emotional experiences and expressions) is linked to better-quality communication, physiological health, psychological well-being, and work performance (for reviews, see Grandey et al. 2013; Lawrence et al. 2011; Mesmer-Magnus et al. 2012; Webb et al. 2012). Findings also show that regulating emotions at the interpersonal-level (i.e. using strategies to regulate the emotional experiences and expressions of others or using others to regulate own emotions) is linked to higher customer service quality and satisfaction and better negotiation outcomes (see Côté et al. 2013); positive client affect and higher perceptions of trust and friendship (Niven et al. 2012a); and more positive perceptions of friendship with colleagues (e.g. Niven et al. 2012b).

Despite these advances, researchers seem to have significantly different ideas about what actually constitutes ER (i.e. its conceptualisation) and how to measure it (i.e. its operationalisation), especially when it comes to interpersonal manifestations. In workplace 
research in particular, ER has been conceptualised in several ways at the interpersonal-level; and this is in part driven by the different underpinning ideas researchers have drawn from individual-level ER models (e.g. Butler and Randall 2013a; Gracia and Ashkanasy 2014; Gross 1998; Humphrey et al. 2015; Williams 2007; Zaki and Williams 2013).

ER has also been operationalised in different ways at both the individual- and interpersonal-levels (e.g. Brotheridge and Lee 2003; Gross and John 2003; Little et al. 2012; Niven et al. 2011) with few attempts to align the operationalisation of ER strategies across levels (see Little et al. 2012 for an exception). This alignment is important for multilevel researchers to be able to partial out the variance attributable to different levels of ER, and also to enable direct comparisons between ER phenomena at different levels (Chan 1998; Klein and Kozlowski 2000).

While recent significant theoretical reviews of the ER literature include Côté (2014), Grandey et al. (2013), Gross (2013b, 2015), and Lawrence et al. (2011), these all focus on ER at the individual-level. What we learn from this literature is that ER at this level in workplace settings is conceptualised using one of three theoretical perspectives: (1) Gross's (1998) ER process model (Gross 2013b, 2015), (2) emotional labor (see Grandey et al. 2013; Humphrey et al. 2015), or (3) Mayer and Salovey’s (1997) ability model of Emotional Intelligence (EI: Côté 2014). These reviews also tend to focus on the commonalities and differences of individual-level ER using the Gross ER process and emotional labor models (e.g. Gross 2013a; Hayward and Tuckey 2013; Mikolajczak et al. 2009). In this regard, we found only one review (Lawrence et al. 2011) that looked at all three individual-level perspectives across a variety of disciplines. Other reviews have critiqued the literature on ER within the context of a larger research goal (Mesmer-Magnus et al. 2012 and Webb et al. 2012 as part of emotional labor and ER process meta-analyses respectively). Importantly, we were unable to locate any reviews of work-related research that examined ER at the 
interpersonal-level from a variety of theoretical perspectives. Understanding interpersonal ER in a work setting is nonetheless important because the quality of working relationships are often developed over time through a series of interactions, and interpersonal ER plays a vital role in shaping the emotional tone of these exchanges.

In response to this shortcoming, our review integrates the extant research on workplace ER at the individual- and interpersonal-levels with the aim to improve our understanding of the phenomenon of interpersonal ER. Our goal is therefore to show the extent to which individual-level approaches to ER have influenced interpersonal-level approaches, and to articulate the strengths and weaknesses of this trend for future development in this field. Thus, the three main approaches to workplace ER at the individual-level (i.e. the process model; emotional labor and EI) are examined initially in this review, and subsequently referenced throughout, to demonstrate the critical role they have played in underpinning the vast majority of ways interpersonal ER has been conceptualised and operationalised by workplace researchers. While we acknowledge that these three approaches are not the only ways that ER can be examined in other contexts (e.g. close romantic relationships, Diamond and Hicks 2005; Kappas 2011; Totenhagen et al. 2016), we contend that these three frameworks have predominantly driven interpersonal ER approaches in organisational settings.

As shown in Figure 1, based on Zaki and Williams (2013), we also develop a 2 x 2 categorisation scheme to demonstrate two additional factors that drive interpersonal ER distinctions in the workplace literature. These factors are interpersonal ER as (1) an intrinsic and/or extrinsic process, and (2) as the activation of those strategies as either responsedependent (depend on another person's feedback) or response-independent (does not require a response from another person). 
The first distinction we make is the extent to which the target of a regulation attempt is intrinsic or extrinsic (Gross 2013b; Zaki and Williams 2013). By intrinsic, we mean regulation in which individuals use their own resources to regulate their own emotions (Gross 2013b). It can also refer to episodes where individuals utilise social interactions with others to regulate their own experiences (Hofmann 2014; Zaki and Williams 2013).

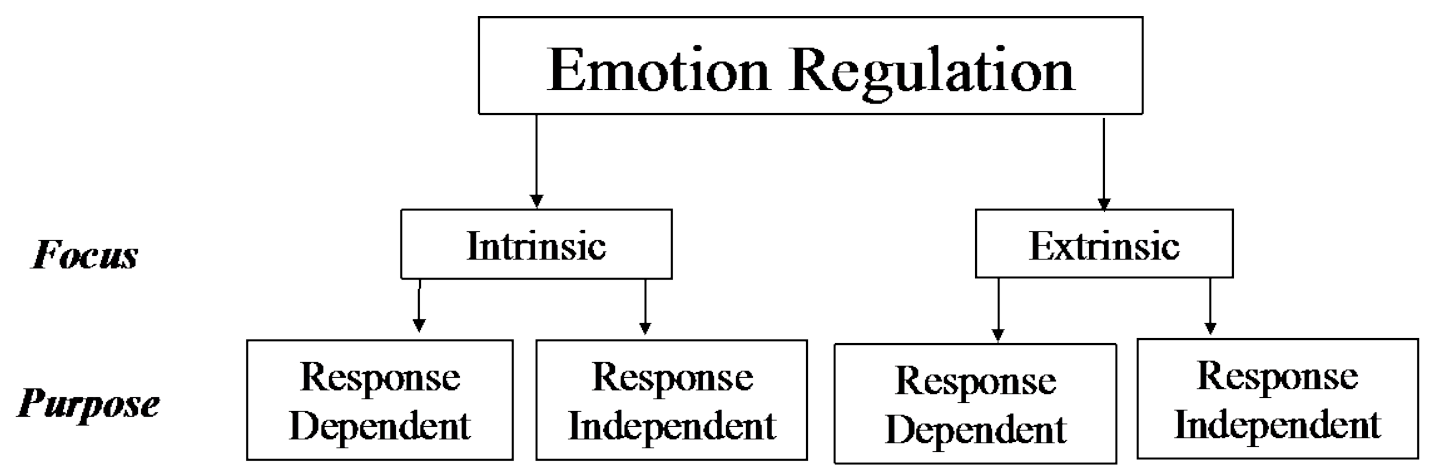

\section{Figure 1. A framework for understanding interpersonal emotion regulation at work}

By extrinsic, we mean regulation in which a person attempts to regulate another person's emotion (Gross 2013; Hofmann 2014; Zaki and Williams 2013). This also refers to repeated episodes in which a person attempts to regulate another person's emotions and requires feedback from the target in order to know that this regulatory goal has been attained (e.g. Ashkanasy and Humphrey 2011; Gracia and Ashkanasy 2014; Zaki and Williams 2013).

The second factor distinguishing theory is the extent to which interpersonal regulation strategies are depicted as response-dependent or response-independent (Hofmann 2014; Zaki and Williams 2013). By response-dependent, we refer to a dynamic regulation process in the sense that verbal and/or non-verbal feedback loop(s) from the target (receiver) act as a signal to the actor (sender) to either maintain or to modify her or his ER strategy (e.g. Ashkanasy and Humphrey 2011; Gracia and Ashkanasy 2014; Zaki and Williams 2013). By response- 
independent, we refer to a static regulation process in which no feedback loop is overtly considered and regulatory goals can be fulfilled in the absence of the interlocutor's response (e.g. Little et al. 2012; Niven et al. 2009, 2011; Zaki and Williams 2013).

In the following review we first examine the commonalities and distinctions in the conceptualisation of ER through the lens of the three dominant theoretical perspectives to clarify the confusion that exists around ER in organisational research. Second, we seek to understand the divergent ways interpersonal ER is conceptualised and operationalised in research, in part due to the different underpinning ideas researchers have drawn upon from individual-level ER models. Third, we seek to identify challenges and avenues for future research regarding this phenomenon. As such, we also respond to Côté's (2005) call for researchers to examine simultaneously the ER phenomenon at individual- and interpersonallevels as a means potentially to resolve seemingly inconsistent findings in the field (e.g. ER and the idea of "psychological strain”).

\section{Conceptualising ER at the Individual Level}

To provide a framework for our review, we first examine scholarly work that has focused on the individual-level of ER. Building partly upon the work of Lawrence et al. (2011), we broaden our scope to encompass the management and organisation literature with a view to analyse three principal theoretical perspectives. Our review demonstrates in particular how each approach deals with significantly different aspects of ER, including ER strategies, ER context, ER goals and (in the context of EI) emotion management; as well as links between ER ability and ER strategy behaviour. In the next section, we highlight how these ideas ultimately impact on the main approaches to interpersonal ER in the management literature. 


\section{Gross’s (1998) Emotion Regulation Process Model}

The most widely adopted ER model in the workplace literature is Gross’s (1998) Process Model of ER. According to this model, ER encompasses the intrinsic strategies involved in "the process by which individuals influence which emotions they have, when they have them and how they experience and express these emotions” (p. 275). These strategies are either antecedent-focused (prior to full development of an emotional experience) or response-focused (after a discrete emotion has been experienced). Gross identified four categories of antecedent ER strategies; situation selection, situation modification, attentional deployment, and cognitive change (e.g. cognitive reappraisal), together with a fifth response-focused category of response modulation (e.g. expressive suppression). More recently, authentic expression of emotion without modification (for reviews see Lawrence et al. 2011; Skinner et al. 2003) has come to be recognised as a valid ER response-focused strategy.

Within Gross's process theory, choice of strategy also depends upon an individual's emotion-related goals and, as such, enactment of a strategy can occur consciously, unconsciously, in isolation, or as part of simultaneous regulation attempts (Tamir 2011). Gross’s (1998) framework provides a theoretically grounded basis to examine a range of ER strategies and to identify how they shape the experience and expression of emotions in the workplace. Importantly, the comprehensiveness of the Gross process model also provides an appropriate baseline framework. As such, it enables us to explore the similarities and distinctions with other conceptualisations of ER strategies in the organisation and management literature and, more specifically, emotional labor and EI approaches.

\section{Emotional Labor}

Hochschild (1983) defines emotional labor as a process involving intrinsic ER strategies where employees are encouraged to regulate their own emotions within 
interpersonal encounters in order to adhere to organisationally mandated emotional display rules (see also Grandey 2000; Grandey et al. 2013). According to Hochschild, when employees are required by an organisation to display specific emotions, they enact one of two ER strategies: surface acting (faking unfelt emotions and suppressing expression of emotions) or deep acting (conscientiously modifying felt emotions to match expressed emotions). Most emotional labor researchers adhere only to these two regulation strategies (e.g. Mesmer-Magnus et al. 2012). Past researchers (e.g. Côté 2005) have equated deep acting with Gross’ (1998) cognitive reappraisal and surface acting with suppression. More recently, Diefendorff et al. (2011) proposed that more ER behaviours are needed when display rules are prominent as compared to situations where individuals are free to display their feelings as they choose. In comparison to Gross’s (1998) more general process model, we identified four aspects where emotional labor has limitations as an explanation of workplace ER.

First, we note that Hochschild (1983) originally proposed emotional labor as a set of behaviours that involve ER strategies to be applied during an employee's interpersonal encounters with customers. In contrast, Gross’s (1998) model encompasses the use of ER strategies under any situational context (i.e. solitary and interpersonal). In an attempt to overcome this constraint, emotional labor scholars have recently begun to extend emotional labor to cover exchanges between colleagues and supervisors (Côté et al. 2013; Grandey et al. 2013; Humphrey et al. 2015). The problem here is that extending the construct of emotional labor (as distinct from ER) to a new interpersonal context, while useful, does not increase our understanding of the regulation phenomenon that occurs in workplaces when employees are on their own.

Second, the notions of deep and surface acting are problematic insofar as they are not conceptually distinct within the existing conceptual domain of ER strategy theory. As several 
researchers (e.g. see Côté 2005; Grandey and Gabriel 2015; Lawrence et al. 2011) suggest, deep acting can be seen as a variant of Gross’s (1998) cognitive reappraisal strategy while surface acting can be viewed as a combination of faking emotional expression and Gross’s expressive suppression strategy. Indeed, depending on the construct definition of deep acting used, it might even incorporate Gross’s attentional deployment strategy category.

Third, Tamir et al. (2008) argues that people often express genuinely felt emotion as a form of ER strategy (see also Lawrence et al. 2011). Although some emotional labor theorists have acknowledged the role of "expression of naturally felt emotion" (e.g. see Ashforth and Humphrey 1993; Grandey et al. 2013; Humphrey et al. 2015), or what they call “automatic regulation” (Beal and Trougakos 2013; Hulsheger et al. 2015) in emotional labor, most empirical research in this field does not explore the role of authentic expression at all (for exceptions, see Diefendorff et al. 2005; Hulsheger et al. 2015). This is because many of these researchers still adhere to the idea that when expressing genuinely felt emotion, no emotional labor per se is required to align the employee's emotional expression with organisational display norms, and therefore it cannot be considered as part of emotional labor. Humphrey et al.’s (2015) recent work hopes to shift more researchers from this view in order to further extend the field of emotional labor.

Fourth, most emotional labor models only consider one emotional goal, viz. adhering to emotional display rules (Grandey et al. 2013). Nonetheless, negotiation and communication researchers argue that ER strategies can also be used to achieve a range of hedonistic and instrumental goals during interpersonal interactions (Perrone and Vickers 2004). For example, Kubiak et al. (2011) argue that individuals use different ER strategies to regulate their experience of anger depending on their communication goal (e.g. avoiding conflicts, taking revenge). This is clearly more in keeping with Gross’s (1998) process model of ER, which allows for multiple regulation goals. 
In brief, the literature generally portrays emotional labor theory as a more restricted set of concepts, namely, intrinsic ER strategies used in interpersonal work contexts to achieve organisational emotional display demands (Becker and Cropanzano 2014; Diefendorff et al. 2011). As such, although emotional labor theory contributes to our understanding of ER at work by focusing on the individual psychological strain such an activity might engender, it is a narrower phenomenon than Gross’s (1998) concept. By contrast, the Gross model is better suited to researchers who wish to examine the generation, experience, and expression of emotion with regard to a wider range of work contexts, incorporating broader ER strategies and/or how ER strategies relate to different instrumental goals.

\section{Emotional Intelligence}

We note confusion when examining ER within the EI literature. Ashkanasy and Daus (2005; see also Jordan et al. 2009; Troth et al. 2012) argue that EI research can be divided into 3 streams, with Stream 1 and 2 conforming to Mayer and Salovey’s (1997) EI ability model (Stream 1 uses ability measures of EI while Stream 2 uses self- or peer-report measures) and Stream 3 conforming to the so-called “mixed models” of EI (i.e. a mix of EI factors and general personality variables; e.g. Boyatzis et al. 2000). The most broadly accepted academic conceptualisation of EI, however is the Mayer and Salovey ability model (see Ashkanasy and Daus 2005; Côté 2014; Jordan et al. 2003), which involves four "branches:” (1) ability to perceive emotion, (2) ability to use emotions to facilitate thought, (3) emotional knowledge, and (4) ability to manage emotion in self and others.

Within the EI literature, the term ER has been used (we argue erroneously) to refer to Mayer and Salovey’s emotion management branch (e.g. see Gratz and Roemer 2004;

Kafetsios et al. 2014; Nelis et al. 2011), defined as the ability to connect, to disconnect or to alter emotional experiences and expressions effectively and appropriately, and do this both 
individually and interpersonally (i.e. influencing others’ emotional experiences). In this way, emotion management can be considered to have both intrinsic and extrinsic influence.

This interchangeable use of the terms ER and emotional self-management continues to be widespread, despite the fact that Mayer and Salovey (1995) clearly distinguish between the two concepts. Indeed, rather than suggesting emotion management and ER strategy are both forms of ER (one an ability and one a behaviour), Mayer and Salovey argue that it is the branches of emotional understanding and emotional self-management that influence the awareness and effectiveness of ER strategy choice. Thus, individuals with high EI abilities are able to choose and to effectively utilise the right regulation strategy flexibly and adaptively to produce discrete emotional experiences and emotional displays that, in turn, help to achieve the individual's instrumental goals in a given context.

Others (e.g. Barrett and Gross 2001; Côté et al. 2008; Geddes and Callister 2007; Lawrence et al. 2011) have also argued that emotion self-management ability is an antecedent of ER behaviour. In this regard, Gross (2015; see also Aldao et al. 2015) has recently coined the concept of ER flexibility, what he defines as an ability to match ER strategy to environmental circumstances. Thus, by integrating EI and ER into a coherent process, this would seem to provide a valid way forward for researchers. In particular, this idea provides a theoretically underpinned foundation for future research and avoids confusion between emotional management and ER.

\section{Summary}

In the foregoing review of individual-level ER, we sought to demonstrate that some of the common ways in which ER has been conceptualised lack the kind of specificity offered by Gross (1998). It appears that the constraints inherent in the emotional labor model affect our capacity to understand what particular ER strategies are useful to achieve goals in various work contexts, as well as the implications of these strategies on employees. In terms of EI, 
the substitution of "regulation" for "management" is imprecise, and so EI per se is not a valid proxy for ER.

Our review of the ER literature at the individual-level within the management and organisation literature thus forms an appropriate basis from which to understand the distinctions between the conceptualisation and operationalisation of ER at the interpersonallevel. It is reasonable to accept that some of the confusion at the interpersonal-level might have emerged from the various ways that ER has been conceptualised at the individual-level. In the following section, we discuss how ER can be conceptualised at the interpersonal-level in a way that takes into account the points we have made so far in this review.

\section{ER at the Interpersonal Level}

As we showed in the preceding discussion, individual ER research has largely focused on explaining how individuals control their own intrinsic emotions. Researchers have more recently begun to recognise that ER attempts are regularly contingent upon the interactions with (and ER choices of) others within social settings. In other words, there is a need to consider ER as a discrete process operating at the interpersonal-level (e.g. see Ashkanasy 2003; Ashkanasy and Humphrey 2011; Côté et al. 2013; Humphrey et al. 2015; Little et al. 2012; Netzer et al. 2015; Niven et al. 2011; Zaki and Williams 2013). To give a practical example, consider an employee who might turn to her colleague or supervisor for assistance in managing her own emotions, or might attempt to regulate a colleague’s or a supervisor's emotional experiences and displays.

As we summarise in Table 1, our review of the workplace literature using the 2 x 2 categorisation shown in Figure 1 reveals four broad approaches to interpersonal ER: (1) as a purely extrinsic process (i.e. only others' emotions are regulated); (2) as a differentiation between the extrinsic interpersonal ER process and the intrinsic individual ER process; (3) as co-occurring intrinsic and extrinsic interpersonal processes; or (4) as the interpersonal 
coregulation of emotion, where interactants actively and dynamically regulate their own and each other's emotional experiences and expressions. Importantly, our review demonstrates that researchers taking one of these four approaches tend to utilise either Gross's ER process model (e.g. Williams 2007; Zaki and Williams 2013), emotional labor (e.g. Côté et al. 2013) or EI models (e.g. Côté 2014; Mayer and Salovey 1997) as a foundation upon which to build their conceptualisations of interpersonal ER in the workplace (and thus necessitating the preceding review of ER at the individual-level). This has, in part, given rise to quite different conceptions and measures about the process(es) comprising this interpersonal construct.

Table 1 also shows that the influence of individual-level theories on interpersonal ER has meant that its dynamic properties have been overlooked in a substantial portion of interpersonal-level ER research. To date, for example, scholars using the Gross (1998) process model and basic emotional labor model only give cursory acknowledgement to the existence of feedback loops in their intrinsic models (i.e. engaging in different ER strategies, or reengaging the same strategy, as initial attempts fail to effectively regulate own emotions). Both theorising and tests of these two models have principally considered intrinsic ER as non-dynamic and response-independent. In the same way, a significant number of interpersonal ER researchers have focused on response-independent extrinsic interpersonal regulation. Table 1 shows that researchers advocating a co-occurrence or interpersonal coregulation approach, however, have attempted to move beyond a static examination of interpersonal ER by incorporating feedback loops (to varying degrees) between intrinsic and extrinsic ER. 
Table 1. Four main approaches to Interpersonal Emotion Regulation using a 2 x 2 Categorisation

\begin{tabular}{|c|c|c|c|c|c|c|}
\hline & & & \multicolumn{2}{|c|}{$\begin{array}{c}\text { Intrinsic } \\
\text { (Regulate own emotions) }\end{array}$} & \multicolumn{2}{|c|}{$\begin{array}{c}\text { Extrinsic } \\
\text { (Regulate others' emotions) }\end{array}$} \\
\hline & & & $\begin{array}{l}{ }^{b} \text { Response- } \\
\text { Dependent }\end{array}$ & ${ }^{\mathrm{C}}$ Response-Independent & Response-Dependent & Response-Independent \\
\hline $\begin{array}{l}\text { Approach to } \\
\text { Interpersonal ER }\end{array}$ & Publications & $\begin{array}{l}\text { Underpinning } \\
\text { Theoretical } \\
\text { Framework }\end{array}$ & & & & \\
\hline \multirow[t]{2}{*}{$\begin{array}{ll}\text { 1. } & \text { Extrinsic Interpersonal } \\
& \text { ER }\end{array}$} & $\begin{array}{l}\text { Friesen et al. }(2013) \\
\text { Little et al. }(2012,2013) \\
\text { Netzer } \text { et al. }(2015) \\
\text { Williams }(2007)\end{array}$ & $\begin{array}{l}\text { Gross ER process } \\
\text { framework }\end{array}$ & & & & $\begin{array}{l}\text { Situation Modification } \\
\text { Attention deployment } \\
\text { Cognitive Reappraisal } \\
\text { Expressive Suppression }\end{array}$ \\
\hline & $\begin{array}{l}\text { Becker and Cropanzano (2014) } \\
\text { Côté (2005) } \\
\text { Côté } \text { et al. (2013) }\end{array}$ & $\begin{array}{l}\text { Emotional Labor } \\
\text { framework }\end{array}$ & & & & $\begin{array}{l}\text { Deep Acting } \\
\text { Surface Acting }\end{array}$ \\
\hline \multirow{3}{*}{ 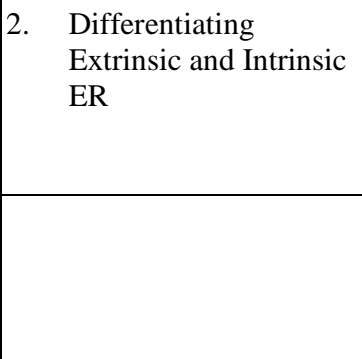 } & $\begin{array}{l}\text { Niven et al. (2009, 2011, 2012a, } \\
\text { 2012b) }\end{array}$ & $\begin{array}{l}\text { Gross ER process } \\
\text { framework }\end{array}$ & & $\begin{array}{l}\text { Intrinsic affect worsening } \\
\text { Intrinsic affect improving }\end{array}$ & & $\begin{array}{l}\text { Extrinsic affect worsening } \\
\text { Extrinsic affect improving }\end{array}$ \\
\hline & $\begin{array}{l}\text { Gracia and Ashkanasy (2014) } \\
\text { Grandey et al. (2007) }\end{array}$ & $\begin{array}{l}\text { Emotional Labor } \\
\text { framework }\end{array}$ & & $\begin{array}{l}\text { Deep Acting } \\
\text { Surface Acting }\end{array}$ & $\begin{array}{l}\text { Deep Acting } \\
\text { Surface Acting }\end{array}$ & \\
\hline & $\begin{array}{l}\text { Côté (2014) } \\
\text { Kafetsios et al. (2014) } \\
\text { Little et al. (2012) } \\
\text { Mikolajczak et al. (2009) }\end{array}$ & $\begin{array}{l}\text { Emotional } \\
\text { Intelligence } \\
\text { framework }\end{array}$ & & Self-Emotion Management & & Other Emotion Management \\
\hline \multirow[t]{2}{*}{ 3. Co-occurrence } & $\begin{array}{l}\text { Campos et al. (2011) } \\
\text { Rimé (2007, 2009) } \\
\text { Zaki and Williams (2013) }\end{array}$ & $\begin{array}{l}\text { Gross ER process } \\
\text { framework }\end{array}$ & $\begin{array}{l}\text { Safe signal } \\
\text { Affiliation }\end{array}$ & Labelling & $\begin{array}{l}\text { Empathy } \\
\text { Prosocial Behaviour }\end{array}$ & $\begin{array}{l}\text { Vicarious experience } \\
\text { Warm glow }\end{array}$ \\
\hline & $\begin{array}{l}\text { Ashkanasy and Humphrey (2011) } \\
\text { Humphrey (2008; 2012) } \\
\text { Humphrey et al. (2008; 2015) }\end{array}$ & $\begin{array}{l}\text { Emotional Labor } \\
\text { framework }\end{array}$ & $\begin{array}{l}\text { Deep Acting } \\
\text { Surface Acting }\end{array}$ & & $\begin{array}{l}\text { Deep Acting } \\
\text { Surface Acting }\end{array}$ & \\
\hline $\begin{array}{ll}\text { 4. } & \text { Interpersonal } \\
& \text { Coregulation }\end{array}$ & $\begin{array}{l}\text { Butler and Randall (2013a, } \\
\text { 2013b) } \\
\text { Saxbe and Repetti (2010) } \\
\text { Troxel (2013) }\end{array}$ & $\begin{array}{l}\text { Affective } \\
\text { attunement; } \\
\text { emotional } \\
\text { synchrony }\end{array}$ & $\begin{array}{l}\text { Morphostatic } \\
\text { processes to maintain } \\
\text { allostatic balance }\end{array}$ & & $\begin{array}{l}\text { Morphostatic } \\
\text { processes to maintain } \\
\text { allostatic balance }\end{array}$ & \\
\hline
\end{tabular}

${ }^{a}$ Based on Zaki and Williams (2013); ${ }^{b}$ Response-Dependent (Depends on the other person's feedback), ${ }^{\text {R }}$ esponse-Independent (Does not require a response from the other person) 


\section{Extrinsic Interpersonal Emotional Regulation}

The first broad approach we address is the view of interpersonal ER phenomena in the workplace literature as an extrinsic process, where only another's emotion is regulated (Gross 2013b; 2015; Little et al. 2012; Netzer et al. 2015; Williams 2007). While extrinsic regulation processes can occur both consciously and unconsciously (Gross 2013b; 2015), the focus of extrinsic interpersonal ER models is on how an individual consciously regulates (or manipulates) the emotions of others using different regulation strategies (e.g. by calming others down in a volatile situation or by making them enthusiastic for a project). Researchers taking an extrinsic approach have variously employed Gross’s (1998) ER process, emotional labor, or EI frameworks to guide the development of their models.

\section{ER Process Model}

Scholars utilising the Gross (1998) framework to conceptualise interpersonal strategies to achieve extrinsic ER goals usually refer to the work of Friesen et al. (2013), Little et al. (2012), and Little et al. (2013), who all build on the work of Williams (2007). In this regard, Williams developed a theoretical framework that comprises four interpersonal ER strategies used to manage others' negative emotions in threatening situations. Table 2 shows how these strategies map directly from four of Gross’s individual strategy categories: situation modification, attention deployment, cognitive reappraisal and response modulation. As depicted in Table 1, researchers taking this approach have conceptualised interpersonal ER as extrinsic and response-independent (i.e. not contingent upon the response of the target to fulfill the regulatory goal). This approach focuses on the actor (sender) using other-focused actions or conversation content (e.g. diverting a co-worker's attention from an unpleasant customer; verbally reframing an email about a reduction in work hours to emphasise the minimisation of job losses) to regulate the target's emotions. Whilst these authors seem not to have taken the opportunity, an advantage of this approach is that the use of these extrinsic 
Table 2. Examples of extrinsic, response-independent interpersonal ER based on Gross’s (1998) process model

\begin{tabular}{|c|c|c|c|}
\hline ER Strategy & What it entails & Situational example & $\begin{array}{l}\text { Scale item examples from Little et al. } \\
\text { (2012) }\end{array}$ \\
\hline $\begin{array}{l}\text { Situation } \\
\text { modification }\end{array}$ & $\begin{array}{l}\text { Removing or altering a problem to reduce the } \\
\text { emotional impact (Williams 2007) } \\
\text { Modifying or changing the situation by removing some } \\
\text { or all of the emotion provoking elements (Gross 1998) }\end{array}$ & $\begin{array}{l}\text { A manager might modify a threat inducing situation by } \\
\text { holding a meeting at a restaurant instead of a boardroom } \\
\text { (Williams 2007) } \\
\text { A vice president of a large institution dealing with anger and } \\
\text { frustration felt by clerical workers worked behind the scenes } \\
\text { to secure a transfer of one of the clerical workers reporting to } \\
\text { a difficult individual (Little et al. 2012) }\end{array}$ & $\begin{array}{l}\text { I remove the negative aspects of the } \\
\text { situation that are negatively impacting } \\
\text { others. }\end{array}$ \\
\hline $\begin{array}{l}\text { Attentional } \\
\text { deployment }\end{array}$ & $\begin{array}{l}\text { Directing the target's attention to something more } \\
\text { pleasant (Williams 2007) } \\
\text { Selecting which aspects of the situation to focus on by } \\
\text { distracting attention away from the elements of a } \\
\text { situation that are harmful to goals, concerns, or well- } \\
\text { being, or by moving away from the situation entirely } \\
\text { (Gross 1998) }\end{array}$ & $\begin{array}{l}\text { A consultant might redirect attention to a hated rival if a } \\
\text { client becomes upset (Williams 2007) } \\
\text { An agent may offer to buy the } \\
\text { target a drink as ways of } \\
\text { distracting targets to improve } \\
\text { their emotions (Little et al. 2012) }\end{array}$ & $\begin{array}{l}\text { When a situation is unpleasant to } \\
\text { others, I refocus them by discussing } \\
\text { positive issues. }\end{array}$ \\
\hline Cognitive change & $\begin{array}{l}\text { Reappraising a situation as more positive (Williams } \\
\text { 2007) } \\
\text { Selecting which of many possible meanings will be } \\
\text { attached to the situation, reappraising or reinterpreting } \\
\text { the situation as having less potential for harm to goals, } \\
\text { concerns, and well-being } \\
\text { (Gross 1998). }\end{array}$ & $\begin{array}{l}\text { A manager might cognitively reframe a pay cut as a way to } \\
\text { mitigate potential job losses (Williams 2007) } \\
\text { When subordinates get angry with a } \\
\text { CEO and vent to their supervisor, } \\
\text { he points out that the CEO wants what is best for the } \\
\text { organisation, reappraising the CEO's demands and } \\
\text { intimidation Techniques (Little et al. 2012) }\end{array}$ & $\begin{array}{l}\text { When I want others to feel less negative } \\
\text { emotion (such as sadness or anger), I } \\
\text { put their problems into perspective. }\end{array}$ \\
\hline $\begin{array}{l}\text { Modulating the } \\
\text { emotional } \\
\text { response }\end{array}$ & $\begin{array}{l}\text { Involving actions that suppress or mitigate an } \\
\text { emotional response (Williams 2007) } \\
\text { Suppressing emotional responses by directly } \\
\text { influencing physiological, experiential, or behavioural } \\
\text { responding (Gross 1998). }\end{array}$ & $\begin{array}{l}\text { A manager might discuss the rejection of an employee's pay } \\
\text { rise request while walking with them to a restaurant or use } \\
\text { deep breathing to modulate her response (Williams 2007) } \\
\text { To calm down an employee when } \\
\text { upset, a supervisor may say something like 'relax' or 'it's not } \\
\text { that big of a deal' or 'calm down.' (Little et al. 2012) }\end{array}$ & $\begin{array}{l}\text { When others with whom I am } \\
\text { interacting are 'venting' about a } \\
\text { problem, I get them to stop. }\end{array}$ \\
\hline
\end{tabular}


interpersonal strategies could be theoretically and empirically compared with Gross’ intrinsic individual strategies.

\section{Emotional Labor}

Some researchers have recognised that emotional labor occurs at multiple levels and can be framed within interpersonal ER (e.g. Ashkanasy and Humphrey 2011; Becker and Cropanzano 2014; Côté 2005; Côté et al. 2013). Both Côté (2005) and Côté et al. (2013), for example, present conceptual models of emotional labor within a dyadic context in which individual actors/senders control their emotions so as to have an impact on a target/receiver. In essence, the sender's regulation of her or his own emotional expression (using individuallevel deep or surface acting strategies) produces changes in the other person's emotions via contagion (e.g. mimicry, entrainment), that then have consequences for the sender (in Côté's 2005 model: work strain). In these conceptual models, the target (receiver) is not viewed as engaging in any form of ER. Rather, the sender’s emotional expressions (via deep or surface acting) are viewed as regulating the receiver/target's emotional experience and expression in a one-way process from sender to receiver. Thus, the focus is on shifting the expression of the self in order to shift the expression of the other. This differs from what we discussed in the previous section, where the sender/actor uses other-focused actions and conversational content (e.g. verbally reframing a negative event for a colleague) to manipulate the target’s (e.g. a customer or colleague) emotional experience and display. In sum, researchers using emotional labor theory and taking an extrinsic approach view interpersonal ER strategies used to influence targets as response-independent (i.e. they don't depend on the response of another to fulfill the regulatory goal) (Zaki and Williams 2013). This occurs via senders’ emotional displays that are subject to the constraints of display rules.

\section{Emotional Intelligence}


Turning now to look at the role of EI in extrinsic interpersonal ER, we note that interpersonal ER scholars drawing on the Gross (1998) framework (e.g. Little et al. 2012; Williams 2007) appear to regard EI in different ways. Williams (2007) argues that EI provides individuals with important emotional knowledge to inform their choice of interpersonal ER strategies and, in this way, Mayer and Salovey’s (1997) EI branch of emotion knowledge positively influences interpersonal ER. Little and her associates (2012, p. 414), on the other hand, view ER as conceptually consisting of both EI (ability) and ER strategy use (behaviour). We agree with the former view, in line with Mayer and Salovey (1997), who argue that emotional understanding and the ability to manage others' emotions directly influence the flexible choice and effectiveness of ER strategy behaviour.

In sum, and as shown in Table 1, some researchers conceptualise interpersonal ER as an extrinsic, response-independent regulation of others' emotional expressions. In the case of those utilising the Gross (1998) ER process model, this involves the regulation of others' emotional experiences as well. Those using the emotional labor model emphasise that selfregulation needs to occur in order to achieve the regulation of others' emotional displays. While those adopting a Gross process model approach argue that the ER strategies of situation modification, attention deployment, cognitive reappraisal, and expressive suppression are involved, emotional labor researchers argue that deep and surface acting strategies are used.

\section{Differentiating Extrinsic Interpersonal from Intrinsic Individual ER}

As can be seen in Table 1, researchers who adopt the second broad approach to interpersonal ER differentiate between ER at the individual- versus interpersonal-level in terms of intrinsic (own-individual) versus extrinsic (other-interpersonal) processes respectively. These scholars (e.g. Hallam et al. 2014; Niven et al. 2009, 2011, 2012a, 2012b) reason that intrinsic ER strategies are inherently individual in nature (see also Gross 2013a, 
2013b). As for the extrinsic approach, it is useful to review the differentiated approach to interpersonal ER using the individual-level frameworks that we identified earlier in this article (process model, emotional labor and EI).

\section{ER Process Model}

Niven and her colleagues are the main proponents of an ER process model approach (Niven et al. 2009, 2011, 2012a, 2012b). Their focus is on controlled (conscious) interpersonal regulation, where individuals seek actively to manipulate the emotional experiences of self and others via four main types of interpersonal ER strategies: (1) intrinsic affect-improving; (2) intrinsic affect-worsening; (3) extrinsic affect-improving, or (4) extrinsic affect-worsening. In deriving these four strategies, Niven et al. (2009) initially reviewed the existing literature that dealt with the controlled or deliberate regulation of someone else's affect (i.e., extrinsic interpersonal ER) to develop a theoretical classification of regulation strategies that they then compared with a list of interpersonal regulation strategies generated and sorted by a series of student samples. Using two general population samples Niven et al. (2011) subsequently developed and tested their four-factor measure to capture both intrinsic and extrinsic regulation by combining Niven et al.'s initial extrinsic interpersonal framework (Niven et al. 2009) with Parkinson and Totterdell's (1999) intrinsic interpersonal regulation framework. Niven and her associates provide examples of negative feedback, criticism, and bullying as examples of affect-worsening extrinsic regulation strategies. They suggest social support provision (e.g. emotional, positive reappraisal) and the use of humour can be considered as examples of affect-improving extrinsic strategies. As shown in Table 1, this approach conceptualises interpersonal ER as extrinsic and responseindependent, in order to fulfill conscious interpersonal goals. Importantly, there is also a focus on the other in this form of extrinsic interpersonal ER, such that it is directly the 
communication content (e.g. telling someone about their shortcomings) that shapes change in the target's emotional experiences and expressions.

The ER strategies referred to by Niven (Niven et al. 2009, 2011, 2012a, 2012b) comprise a wide net of constructs that move beyond the conceptual boundaries of Gross's (1998) categories, and even the interpersonal strategies proposed by coping researchers (see Skinner et al. 2003). Consequently, there is a risk that interpersonal ER might be conflated with other (albeit related) constructs such as coping and anti-social behaviour. Niven and her colleagues have tried to ensure nonetheless that there is conceptual equivalence between the specific strategies directed at the individual intrinsically (e.g. giving oneself negative feedback) versus the interpersonal target extrinsically (e.g. negative feedback towards another). This is especially helpful for future researchers wishing to establish the relative importance of extrinsic as compared to intrinsic ER behaviours.

\section{Emotional Labor}

As we have already highlighted, we found in our review that researchers increasingly recognise that emotional labor occurs at multiple levels and can be framed within interpersonal ER. In contrast to the extrinsic approach taken by Côté and his colleagues (Côté et al. 2005, 2013), Gracia and Ashkanasy (2014) present a multilevel conceptual view of emotional labor that aligns more with the differentiated approach to interpersonal ER. These authors view interpersonal emotional labor as flowing in both directions between the employee and customer in a reciprocal process. Grandey et al. (2007) take a similar view in examining how employees use emotional labor when encountering verbal abuse from customers. They advocate that an employee's subsequent emotional expressions are influenced by the target's emotional expressions. To clarify the process further, the employee initially focuses on the self and regulates her or his own emotional expressions (i.e. via surface or deep acting in accordance with organisational display rules; intrinsic and response- 
independent) in order to influence the angry customer (i.e. the target). The customer's potential change in emotional expressions in turn partially shapes the employee's subsequent emotional expressions to further extrinsically regulate the targets' emotions (i.e. extrinsic and response-dependent).

While we recognise that the employee is not consciously approaching the customer to manipulate his or her own emotion initially, emotional labor scholars taking this approach appear to believe that a feedback loop is likely to be an unintended consequence of such exchanges. This means that the need to achieve the extrinsic regulatory goal of changing a customer's emotional expressions necessitates the employee to take into account feedback and then engage their intrinsic ER strategies to control their expressions. We would argue, however, there is only a minor response-dependent influence in this case as the employee would still use their own response-independent judgement of how best to regulate their own emotional experiences and expressions whilst adhering to organisational display rules.

\section{Emotional Intelligence}

Researchers taking a differentiated approach to interpersonal ER (e.g. Niven et al. 2009, 2011, 2012a, 2012b) tend to argue for a somewhat overlapping relationship between ER strategies and the EI branches of self-emotion management and management of others' emotions. In particular EI's emotion management ability is viewed as an "ability level form” of ER (similar to Kafetsios et al. 2014; Little et al. 2012; Mikolajczak et al. 2009). Our concern is that current arguments about ability versus behavioural forms of ER are too simplistic and potentially mislead novice scholars about the true nature of these concepts and their theoretical relationship (Mayer and Salovey 1995). For instance, Côté (2014) argues that the EI abilities of self- and other-emotion management (which he calls ER) involve the ability to set ER goals and to select and to implement ER strategies correctly and effectively. This is quite different to the broader ER process approach involving ER strategies described in the 
preceding section of this essay. As a result of this overlapping terminology, it is likely that scholars will continue to use EI branches either to measure interpersonal ER per se or to assess the construct convergent validity of scales developed to measure interpersonal ER (i.e. EROS scale, see Niven et al. 2011).

In sum, our review of research taking a differentiated approach suggests emotional labor scholars view intrinsic ER as mostly response-independent and extrinsic ER as response-dependent. By contrast, other researchers using the process model differentiate response-independent interpersonal (extrinsic) ER from response-independent individual (intrinsic) ER. These latter scholars are more inclined (erroneously) to argue that the ER process conceptually consists of both interpersonal ER strategies (behavioural form) and EI's emotion management of others (ability form).

\section{Co-occurring Extrinsic and Intrinsic Interpersonal Emotion Regulation}

Another, less common, approach to interpersonal ER (as depicted in Table 1) is to consider how intrinsic and extrinsic ER processes might co-occur within a relationship (e.g. Campos et al. 2011; Rimé 2007, 2009; Zaki and Williams 2013), a truly interpersonal-level approach. Scholars adopting this approach argue that it is important to distinguish between two types of interpersonal ER processes: intrinsic interpersonal regulation, in which an individual initiates social contact with another to regulate her or his own emotional experiences, and extrinsic interpersonal regulation, where an individual attempts to regulate another's emotional experiences and expressions. This contrasts markedly with the differentiated approach (which we reviewed earlier) as, in this case, interpersonal ER processes are seen simultaneously to involve both the regulation of the actor's own emotional experiences (intrinsic) and the regulation of the target's emotional experiences (extrinsic) that can be either feedback-dependent or response-independent. Thus, in essence ER 
strategies enacted during intrinsic regulation while focused on the actor's own emotions come to be viewed as interpersonal in nature.

This combined intrinsic and extrinsic approach encapsulates a social sharing of emotions and is a much more comprehensive and broader view of interpersonal ER than the previous ones we reviewed, especially when compared to models used by researchers who strictly ascribe to Gross's (2013a) process model. To understand this view further, it is useful to refer to Zaki and Williams’s (2013) framework - that builds on Rimé’s (2009) conceptualisation of interpersonal ER. As shown in Table 1, Zaki and Williams distinguish between intrinsic and extrinsic ER strategies by focusing on those responses that are overtly interpersonal in nature (e.g. empathy, social support, emotion expression, prosocial behaviour), and whether or not these strategies form part of either response-dependent (i.e. rely on the particular qualities of another person's feedback) or response-independent processes (i.e. occur in the context of social interactions, but do not require that another person respond in any particular way). Zaki and Williams argue in particular that their model explains inconsistent effects found in previous research on interpersonal ER such as contrasting findings for the sharing of emotions (Rimé 2009).

In this regard, Zaki and Williams (2013) reason that ER goals emerge in a process of social sharing that encourages individuals to regulate their own or another's affect. In terms of intrinsic response-dependent strategies, for instance, the supportive (i.e. responsive) behaviours of others provide what is described as a safe signal or sense of affiliation that enables an individual to reconsider the events that led to his or her emotion. This reappraisal can then diminish the experience of a stressful event and alter an individual's responses to such events. By contrast, labelling is a type of intrinsic response-independent mechanism that does not rely on another person's response. The rationale here is that the mere act of communicating emotions to others enables individuals to label their affective states and the 
sources of those states, thus requiring appraisal of their own felt emotion. This appraisal, in turn, enables regulation by lessening the ambiguity of the individual's emotional state to facilitate coping. Zaki and Williams describe how, during an enduring relationship, the use of safe signals and affiliation might lessen in favour of the independent-response strategy of labelling. Thus, it appears that a less constrained response from (or the mere presence of) others can suffice to regulate an individual's emotion.

Moreover, in terms of extrinsic interpersonal ER, empathy (see Zaki et al. 2008) and prosocial behaviour are presented as aspects of other-focused behaviour. For empathy, the target's (or other's) use of expressive behaviour is a necessary “input.” Empathy is viewed as involving the individual understanding the other's state and sharing of that state; both facets depending on the target’s ability to express their affect clearly. Another important subcomponent of this response-dependent process is the individual's motivation to alter the trajectory of the other's emotional experience (the extrinsic regulatory goal). Using this framework, an individual can utilise empathetic processes through prosocial behaviours, such as providing the other with situation-specific emotional support, comforting messages, diffuse support not associated with a single event, or practical support such as providing material resources (Zaki and Williams 2013).

Offering prosocial support may be viewed in particular as an important way to regulate another person's behaviour, even if it does not always guarantee regulation of the other's affect (Bolger et al. 2000). In this regard, Zaki and Williams (2013) argue that, if someone succeeds in their regulatory goals towards another by offering prosocial support, the feedback from that target can also improve the individual's own affective state. This occurs through the individual vicariously experiencing the affective impact of his or her own prosocial actions on another. Thus Hein et al. (2010) and Morelli et al. (2014) link neural and behavioural research to reveal that experiences of strong vicarious affect are related to the use 
of prosocial behaviour as a form of ER. Finally, extrinsic response-independent processes are regulatory goals that can be achieved without the other's response. Zaki and Williams (2013) discuss how engaging in prosocial behaviour leads to positive affect (labelled as a "warm glow”) that can occur irrespective of the consequences for the other resulting from these acts.

\section{Emotional Labor}

There has also been growing interest in leadership and emotional labor research ('leading with emotional labor' is a phrase coined by Humphrey 2008) over the last decade that suggests alignment to the co-occurrence approach of interpersonal ER. Indeed, simultaneous use of response-dependent intrinsic and extrinsic strategies appears to be implicit in this approach to emotional labor at the interpersonal-level. Several researchers have theoretically examined how leaders use emotional labor tactics (e.g. Ashkanasy and Humphrey 2011; Humphrey 2008; Humphrey et al. 2008) not only to manage their own moods, but also to improve the moods of their followers. Humphrey (2012) suggests that leaders can influence their subordinates’ feelings through a process of emotional contagion; he goes on to discuss how leaders can use emotional labor as a form of ER to take conscious control of their own emotions so that they can express appropriate emotions to their followers and, through emotional contagion, the followers feel the leaders' experienced emotions, display congruent emotional expressions and, in turn, pass on the emotions to other group members or clients. Ashkanasy and Humphrey (2011) also discuss how, via emotional contagion, effective leaders create an emotional resonance that emotionally synchronises leaders and followers.

In sum, while Zaki and Williams’s (2013) approach is relatively recent, our review shows that other researchers are beginning to build on this approach to consider the role of interpersonal ER in specific contexts. For example, Hofmann (2014) adopted this model to 
explain conceptually how mood and anxiety disorders are regulated and maintained through others. Neurobehavioural researchers such as Rameson et al. (2012) and Zaki et al. (2008) also draw on aspects of Zaki and Williams’s model to frame their research regarding the extrinsic response-dependent and independent ER strategies of empathy and prosocial behaviour.

\section{Interpersonal Coregulation of Emotion}

The three approaches to interpersonal ER we have reviewed thus far highlight the need to consider the social context of ER. Nonetheless, to a large extent, the ways in which interpersonal ER has been conceptualised in research to date still fall short of encapsulating the dynamic processes involved in many interpersonal ER encounters. The fourth and final approach to interpersonal ER we review focuses specifically on the flow of emotion between two individuals, where the partners seek to help each other actively and dynamically in order to manage their emotional expressions and states (e.g. see Butler and Randall 2013a, 2013b; Saxbe and Repetti 2010; Troxel 2013). Also known as affective attunement or emotional synchrony, we refer to this reciprocal process as "coregulation of emotion" in line with Butler and Randall's (2013a) terminology. This label captures the reciprocal nature of the process. Thus, during coregulation, one person attempts to enhance or suppress her or his personal emotion based on the reactions of another person who, in turn, seeks likewise to enhance or suppress his or her personal emotion. Thus, coregulation is an interactive and dynamic process of mutual ER. Of the three broad approaches described in the above sections, Zaki and Williams’s (2013) response-dependent (intrinsic and extrinsic) processes most closely aligns to this concept of coregulation.

Emotional coregulation has emerged primarily from the adult close relationship literature (Butner et al. 2007; Saxbe and Repetti 2010; Sbarra and Hazan 2008; Totenhagen et al. 2016). Yet it also has clear applicability (and implications) for workplace affective 
relationships. There is plenty of evidence to show close affective workplace relationships often emerge in the context of mentoring or when teams are working under pressure to meet deadlines or when colleagues work together for significant periods of time (e.g. McAllister 1995). Butler and Randall (2013a) discuss how the coregulation construct encapsulates the constant interchange of emotions between individuals that provides a degree of emotional stability for those involved. An important feature of coregulation is that it is a unique dyadiclevel phenomenon that cannot be reduced to the behaviours or experiences of the individuals involved (Butler and Randall 2013a; Cole et al. 2004). In this regard, the emphasis is not on the actor's or the target's ER, but rather on the ways in which both partners attempt to influence each other in a recursive pattern of mutual regulation.

Butler and Randall (2013a) also identify coregulation as a special or distinct form of interpersonal ER. They argue that many emotion regulatory efforts are targeted at changing either a social partner's emotions or the emotional tone of the relationship, and that these efforts constitute specific examples of interpersonal ER (i.e. extrinsic approach; individual intrinsic/extrinsic interpersonal approach), rather than coregulation per se (cf. Niven et al. 2009). To illustrate, Butler and Randall explain that making a team member feel guilty so s/he will comply with a demand is a form of extrinsic interpersonal regulation, not coregulation. That is, extrinsic interpersonal regulation does not require a bidirectional process (unlike coregulation). On the other hand, an interactive process that results in emotional progression and growth of understanding between individuals (e.g. supporting a colleague emotionally through a difficult change process via listening, conveying empathy, providing distractions) is seen as leading to coregulation because, in this instance, emotions change over time between the two individuals. 


\section{Summary of Interpersonal Emotion Regulation Conceptualisations}

To varying degrees, the extent to which one person attempts to up-play or down-play the emotion of self and/or other is captured in the interpersonal approach to ER. Similar to our earlier discussion of individual ER, our review of the literature reveals that considerable blurring occurs between related concepts and processes at the interpersonal-level of ER, in part caused by the different individual-level models on which interpersonal ER conceptualisations are based. As shown in Table 1, researchers in this domain also differentially focus on conscious extrinsic ER processes, intrinsic (individual) and extrinsic ER processes and coregulation processes. Consequently, conceptualisations of interpersonallevel ER strategies have varied according to different foci (intrinsic actor-focused strategies, extrinsic target-focused interpersonal strategies, and reciprocal coregulation).

It is clear that researchers need to think carefully about the ER approach they choose and to explain how their selection aligns with their research aims. For instance, if research is concerned with the one-way regulation of another's emotion, then an extrinsic approach is suitable, with Gross’s (1998) model being most appropriate if the researcher is interested in the regulation of another's experience and expression of emotion as opposed to an emotional labor lens in which the focus is narrowed to the regulation of another's expression (in the context of display rules). Overall, researchers interested in studying interpersonal ER (as a two-way process) would do well to regard coregulation as the most conducive approach. As we review in more detail next, however, the limited measures available to assess coregulation provide additional challenges and opportunities for researchers.

\section{Operationalising Emotion Regulation at the Interpersonal Level}

Having reviewed the four main approaches to conceptualising interpersonal ER in the literature, it is now important for us to examine the main ways researchers have 
operationalised interpersonal ER in empirical research. In doing this, we follow the same structured approach used in the preceding sections.

\section{Extrinsic Interpersonal Emotional Regulation}

\section{ER Process Model}

Gross and John (2003) were the first to develop a measure of individual ER, which they called the ERQ (Emotional Regulation Questionnaire). Consistent with Gross’s (1998) original process model, the ERQ measures two dimensions: (1) expressive suppression (4 items; e.g. "I keep my emotions to myself”); (2) cognitive reappraisal (6 items; e.g. "When I want to feel less negative emotion, I change the way I'm thinking about the situation”).

Notably, scholars have recently begun to adapt the ERQ for use in interpersonal situations. For example, Kafetsios et al. (2012) used the ERQ to investigate how the individual ER strategies of two employees (e.g. supervisor and employee) within a relationship interact to influence outcomes at the individual level. Results showed that a supervisor's use of reappraisal has a positive moderating effect on the relationship between her or his subordinate's use of reappraisal and their job satisfaction and positive affect (and lower negative affect). A further finding was that a supervisor's use of suppression is related to a reduction in positive work outcomes for subordinates who report higher suppression. Kafetsios et al. (2014) also utilised the ERQ to examine how individual ER strategies used by medical practitioners affect their patients’ satisfaction ratings, with similar results. Kafetsios and his colleagues' work paves the way for operationalising interpersonal ER by demonstrating how the ER of two individuals can combine to influence target (employee and patient) outcomes.

Although the work of Kafetsios and his colleagues (2014) advances our knowledge about ER, their research was still essentially conducted at the individual-level, albeit within an interpersonal context. In contrast, as shown in Table 2, Little et al. (2012) used a more 
direct approach. Building on Williams’s (2007) conceptualisation of interpersonal ER, Little and her team developed and validated a 20-item self-report measure that they called the “Interpersonal Emotion Management Scale” (IEM). The IEM is intended to measure behaviours targeted specifically at managing the negative emotions of others. As such, it captures four interpersonal ER strategies of situation modification (e.g. "I change the situation to alter its emotional impact”), attentional deployment (e.g. "When a situation is disturbing others, I focus their attention away from the troubling aspect of the problem”), cognitive change (e.g. "I try to influence the emotions of others by changing how they think about the situation they are in”) and modifying the emotional response (e.g. "I encourage others to keep their emotions to themselves”). In a follow-up study of emotional labor, Little et al. (2013) modified the IEM to investigate how customer-focused ER strategies (used by customer service representatives) affect expressed customer emotions. In sum, the IEM appears to be a valid assessment tool for researchers studying extrinsic interpersonal ER.

\section{Emotional Intelligence}

While some researchers have used Stream 2 EI measures (see Ashkanasy and Daus 2005; Jordan et al. 2009) to assess interpersonal ER, more specific measures have begun to appear. For example, Curşeu et al. (2012) attempted to develop their own group-level measure of ER. On close examination of the items in this measure, however, it becomes clear that the measure overlaps with other broad measures of EI in teams (i.e. the WEIP-S: Workgroup Emotional Intelligence Profile; Jordan and Lawrence 2009). This is in contrast to Little et al.’s (2012) use of measures of EI as a form of discriminant validity when developing interpersonal ER measures such as the IEM. It appears that the confusion surrounding the EI ability of emotion management at the individual level - and whether or not it is (or is not) a form of ER - has carried across to the interpersonal level. This is further demonstrated in the following discussion, where we review the various measurement 
approaches that align to a differentiated intrinsic individual and extrinsic interpersonal approach to interpersonal ER.

\section{Differentiating Extrinsic Interpersonal from Intrinsic Individual ER}

So far in in this review, we have examined a differentiated view of interpersonal ER that encapsulates intrinsic ER (individual-level) and extrinsic ER (interpersonal-level) strategies (Gross 2013; Hallam et al. 2014; Niven et al. 2009, 2012a, 2012b). We now look in more detail at how researchers taking this perspective have operationalised interpersonal ER, specifically in relation to the Gross (1998) and EI models. As far as we can ascertain, no one to date has employed an emotional labor perspective to operationalise this approach.

\section{ER Process Model}

Niven et al.’s (2011) 10-item measure of “Emotion Regulation of Others and Self” (EROS) reflects the differentiated model of interpersonal ER. The EROS measure captures four types of interpersonal ER: (1) intrinsic affect-improving (e.g., "I thought about something nice”); (2) intrinsic affect-worsening (e.g., “I expressed cynicism”); (3) extrinsic affect-improving (e.g., “I made someone laugh”); and (4) extrinsic affect-worsening (e.g., “I told someone about their shortcomings”). Note in particular that the items used by Niven and her colleagues in this scale are quite different to the items used by Little et al. (2012). It is conceivable that interpersonal ER per se is not being captured in this view because it appears that individual-level data is collected to capture the individual-level strategies that two individuals use towards one another within a relationship context. Niven et al. partly acknowledge this when discussing how their findings may be caused by within-person individual processes, including how individuals anticipate a target might respond to regulation attempts (Niven et al. 2012b).

In subsequent empirical work using the EROS measure (using student and prison staff samples), Niven et al. (2012b) found relationships between an individual's use of 
interpersonal ER (on others) and her or his own affective well-being. In particular, Niven and her team found that individuals who self-regulate their affect are considered to have better interpersonal ER when working with others (via complimenting, listening to another's problems, or joking) as well as their own well-being. On the other hand, by engaging in negative behaviour towards others (via criticising, ignoring, or using aggressive tones or words), individuals not only run the risk of worsening their relationships with others, but also are likely to degrade their own well-being.

Niven et al. (2012a) report further that interpersonal affect-improving strategies (as measured by the EROS) influence the quality of people's workplace relationships (employees; prisoners, and wardens). In particular, they found that attempts by an individual to improve another's affect via particular affect-improving strategies are associated with their own and the target's perceptions of friendship and trust.

One new and potentially fruitful approach to interpersonal ER may be found in a recent study by Hallam et al. (2014). Citing the Niven et al. (2009) conceptualisation of interpersonal ER, Hallam et al. (2014) examined neurophysiological processes while subjects engaged in interpersonal ER. In this study, 20 participants viewed a series of short sad or disgusting videos while undergoing fMRI scans. While watching the videos, participants were instructed to regulate either their own (individual condition) or another person's (interpersonal condition) emotional state using one of three ER strategies (suppression, reappraisal, just watching). Results revealed that undertaking individual and interpersonal ER tasks draws on overlapping networks of brain regions. More importantly, activations unique to the interpersonal condition suggest that both affective (emotional simulation) and cognitive (mental) aspects of empathy are involved in interpersonal ER processes. 


\section{Emotional Intelligence}

As we have already discussed, Stream 2 EI measures have also been used inappropriately as proxies for both intrinsic individual and extrinsic interpersonal ER. Like Little et al. (2012) - who used a measure of EI to establish discriminant validity with their interpersonal ER measure - Niven et al. (2011) promoted EROS as a behaviour-based ER measure (as opposed to EI which they view as an ability-based ER measure) and utilised Tett et al.'s (2005) Survey of Emotional Intelligence (SEI; specifically, a scale measuring the ability to regulate others' affect) to establish EROS's construct validity. In this way, they are conceptualising EI as consisting of both ER ability and ER behaviour; a view that is at odds with Mayer and Salovey (1995) (see also Côté 2014; Lawrence et al. 2011).

Our point here is that it is important to differentiate between measures of EI and ER. The use of EI measures in this way is consistent with the view that the construct represents a specific form of human ability rather than a trait. As such, EI might better be seen to potentiate ER rather than serve as a proxy measure for it (as either an intrinsic or an extrinsic process phenomenon).

\section{Co-occurring Extrinsic and Intrinsic Interpersonal Emotion Regulation}

As we reviewed earlier, the combined approach to interpersonal ER considers how both self- and other-affect is regulated within a relationship (Zaki and Williams 2013). Minimal empirical work has been conducted using this approach, however, and none examines all aspects of the model simultaneously (i.e. intrinsic vs extrinsic; responsedependent vs response-independent strategies). Despite the many advantages of a simultaneous approach (cf. Zaki and Williams 2013), its major weakness is the "lack of available instruments available to measure the interpersonal ER strategies” (Hofmann 2014, p. 490). In particular, there appears to be an absence of specifically developed measures of interpersonal ER that simultaneously capture intrinsic and extrinsic ER. 
More recently, neural studies (i.e. using fMRI or other neuroscience methods) have begun to emerge that explicitly addresses the Zaki and Williams (2013) interpersonal ER framework. These studies tend to focus on neural pathways linked to the specific otherfocused interpersonal ER strategies of empathy (extrinsic, response-dependent) or prosocial behaviour (extrinsic, response-independent). Examples can be found in the work of Rameson et al. (2012), who studied empathy and prosocial behaviour; and research by Hein et al. (2010), who examined prosocial behaviour and help-giving to others.

Of particular relevance is the consistent finding across all these studies that the neural pathways activated for ER are associated with responses to the behaviours of others. Results by Zaki et al. (2008) also provide evidence that targets’ and perceivers’ traits should be modelled simultaneously, especially insofar as they can interact with each other. Thus, it seems that the interpersonal approach to empathic accuracy dovetails with statistical and theoretical models of person-perception accuracy that involves unique interactions between perceivers and targets (cf. Kenny and Albright 1987). It is important to note here that cooccurrence essentially represents a static process, while coregulation is dynamic.

\section{Interpersonal Coregulation of Emotion}

Measurement of coregulation is still developing. As such, there are specific operational and analysis challenges involving research in this area (Butler and Randall 2013b; Troxel 2013). Troxel (2013) in particular contends that the coregulation approach to ER has been hindered by the lack of a precise operational definition of coregulation. This has impeded the development of reliable and valid measures in particular. According to Butler and Randell (2013a), coregulation is a bidirectional linkage of oscillating emotional channels (subjective experience, expressive behaviour, and autonomic physiology) between partners, which contributes to the emotional and physiological stability for both partners in a close 
relationship. One challenge is to more carefully distinguish coregulation from related constructs such as stress buffering or emotional contagion (Butler and Randall 2013b).

Based on our review of the work of Butler and Randall (2013a, 2013b; see also Troxel, 2013), it is clear that three criteria need to be satisfied to develop an operational definition of coregulated ER. First, coregulation requires bidirectional statistical dependence between relationship partners over time on some measure of emotion. Second, it entails relationship partners' emotions to be oscillating in a coupled fashion around a fluctuating optimal level that is globally stable (meaning that it is dominated by negative feedback processes to dampen or reverse deviations that maintain overall emotional stability). Third, if coregulation is relevant to allostatic balance (maintaining balance during change), it should be most obvious when one or both partners are agitated away from a balanced state and would appear as dampening oscillations converging on a more optimal level given internal and external demands (cortisol, oxytocin levels between couples are put forward as possible measures).

In particular, Troxel (2013) questions Butler and Randall’s (2013a) position that coregulation is merely “a bidirectional linkage of oscillating emotional channels (subjective experience, expressive behaviour, and autonomic physiology) between partners, which contributes to emotional and physiological stability for both partners in a close relationship” (p. 203). Troxel also highlights the notion that coregulation involves a morphostatic process that allows dyads dynamically to organise and to influence each other's behaviours within an optimal “set point” (Feldman 2007; Sbarra and Hazan 2008). This latter distinction is particularly useful for distinguishing coregulation from other related, but distinct, constructs such as "synchrony” or emotional contagion. Thus, while harmonious dyads may or may not be synchronous in terms of affect, behaviour, and physiology, what is uniquely powerful 
about coregulation is that it suggests that healthy couples will covary along these dimensions within certain bounds that maintain optimal well-being.

\section{Summary of Interpersonal Emotion Regulation Operationalisations}

From the foregoing review, it should be clear that the operationalisation of interpersonal measures of ER and the resulting empirical evidence is still developing (see Niven et al. 2012a, 2012b). Reiterating the point made by Zaki and Williams (2013), clearer conceptual and theoretical groundwork needs to be established to resolve inconsistencies in interpersonal ER perspectives, especially the interplay between individual and interpersonal regulation processes. Our view is that refining and clarifying these distinctions will allow for a more cohesive program of measurement development and empirical work from the field as a whole. At present, there seems to be considerable confusion about what constitutes interpersonal ER. There also appears to be significant measurement issues around levels of analyses. Some researchers are using individual-level measures to assess dyadic phenomena; others are attempting to develop measures that consider ER within an interpersonal relationship, while others are attempting to assess covariation.

\section{Future Directions}

In this review, we have demonstrated the divergent ways in which individual and interpersonal ER are being conceptualised and operationalised in organisational research. We critiqued current conceptualisations of ER to provide clarity and consolidate the work on ER to date at the individual- and interpersonal- level. This is timely given the burgeoning publications in the area and the confusion that is emerging with regards to both conceptualisation and measurement. In this section, consistent with our identification of three approaches to conceptualising ER, we highlight four main messages for future researchers to advance this field. 


\section{Message 1: Coregulation.}

The idea of coregulation appears to be viable in both conceptualising and operationalising interpersonal ER. Nonetheless, there is still a long way to go before this construct is fully understood. As such, the idea remains controversial as exemplified in the exchange between Butler and Randall and Troxel (see Butler and Randall 2013a, 2013b; Troxel 2013). Clearly, more work is required to progress this promising advance in the field.

\section{Message 2: Measurement}

Future researchers need to decide whether to focus on further developing Gross’s (1998) process approach (more narrow and extrinsic) or take a broader two-way approach (as per Zaki and Williams 2013; Butler and Randall 2013a). In particular, researchers need to move away from self-report measures and to employ more objective or neurobiological measures (e.g. see Chapman et al. 2015; Hallam et al. 2014; Seeley et al. 2015).

\section{Message 3: Biological Bases of ER}

Addressing the future of research in the organisational behaviour discipline, Ashkanasy (2009) noted that there is a prima facie case to look more closely at the common biological bases of ER in the context of organisations (see also Healey and Hodgkinson 2014). For example, Hobson et al. (2014), in a study of the neurophysiological effects of ER, found that it reduces cognitive control. Since cognitive control is a pre-requisite for effective performance in organisations (Carayon and Smith 2000), it would seem to follow that seeking to understand the biological bases of ER is likely to be a fruitful area for future research. In this regard, one of the more exciting approaches to interpersonal ER has emerged in the neural circuit studies we looked at in this review (e.g. Hallam et al. 2014; Seeley et al. 2015).

\section{Message 4: The Importance of Context}

Healey and Hodgkinson (2014, p. 780) note that organisations “actively create the external structures that constrain their ongoing processes of thinking and feeling.” With 
specific regard to studies of emotional labor, Diefendorff and Gosserand (2003) have shown how organisational “display rules” constrain employees’ use of ER strategies (i.e., emotional labor). This view is also consistent with Ashkanasy’s (2003) multilevel model of emotions in organisations, where influences at the organisational and group levels shape individual employees' interpersonal relationships with others in the organisation. Clearly, accounting for context in the process of ER will become even more important as the focus moves to the interpersonal-level for researchers. Dyadic interchanges at work are driven by normative expectations of both the workplace and colleagues and on this basis, these expectations cannot be ignored when examining processes of ER. We clearly need more focus on context in ER research going forward.

\section{Conclusion}

Over the last couple of decades there has been growing interest in the role of ER in the workplace context. The fact that ER occurs at multiple levels is now also gaining research traction as scholars recognise that ER processes in organisations rarely occur in a social vacuum and are typically part of the interpersonal milieu underpinning workplace relationships. As we have highlighted, a number of diverse approaches to the conceptualisation and operationalisation of interpersonal ER have emerged that have largely arisen from the influence of three major individual-level ER models. In some cases, this has led to quite divergent views about what constitutes interpersonal ER and how it should be measured. We argue this trend has the potential to stymie research development if scholars don't take stock of the state of play with a view to moving forward with greater clarity. To assist with this process, in this review we demonstrated how interpersonal ER theory utilised in work contexts tends to fall into four groupings, and the strengths and weaknesses of each approach. We also call on researchers to think more carefully about the ER approach they choose and to explain how their selection aligns with their research aims and their 
explanation of workplace phenomena. Finally, we appeal to scholars to direct further research into more effective (and innovative) ways to measure interpersonal ER. We hope our review contributes to what is an exciting area for researchers to pursue over the next decade.

\section{References}

Aldao, A., Sheppes, G. and Gross, J.J. (2015). Emotion regulation flexibility. Cognitive Therapy and Research, 39, pp. 263-278.

Ashforth, B.E. and Humphrey, R.H. (1993). Emotional labor in service roles: The influence of identity. Academy of Management Review, 18, pp. 88-115.

Ashkanasy, N.M. (2003). Emotions in organizations: A multilevel perspective. In Dansereau, F. and Yammarino, F.J. (eds), Research in Multi-level Issues, Volume 2: Multi-level Issues in Organizational Behavior and Strategy. Oxford, UK, Elsevier Science, pp. 9-54.

Ashkanasy, N.M. (2009). After thirty years: What does the future hold? Journal of Organizational Behavior, 30, pp. 15-20.

Ashkanasy, N.M. and Daus, C.S. (2005). Rumors of the death of emotional intelligence in organizational behavior are vastly exaggerated. Journal of Organizational Behavior, 26, pp. 441-452.

Ashkanasy, N.M. and Humphrey, R.H. (2011). A multi-level view of leadership and emotions: Leading with emotional labor. In Bryman, A., Collinson, D., Grint, K., Jackson, B. and Uhl-Bien, M. (eds), The Sage Handbook of Leadership. London, UK: Sage, pp. 363-377.

Barrett, L.F. and Gross, J.J. (2001). Emotional intelligence: A process model of emotion representation and regulation. In Mayne, T.J. and Bonanno, G.A. (eds), Emotions: Current Issues and Future Directions. New York: The Guilford Press, pp. 286-310. 
Beal, D.J. and Trougakos, J.P. (2013). Episodic intrapersonal emotion regulation: Or, dealing with life as it happens. In Grandey, A., Diefendorff, J. and Rupp, D. (eds), Emotional Labor in the $21^{\text {st }}$ Century: Diverse Perspectives on Emotion Regulation at Work. New York: Routledge, pp. 31-55.

Becker, W.J. and Cropanzano, R. (2014). Good acting requires a good cast: A meso-level model of deep acting in work teams. Journal of Organizational Behavior, 36, pp. 232-249.

Bolger, N., Zuckerman, A. and Kessler, R.C. (2000). Invisible support and adjustment to stress. Journal of Personality and Social Psychology, 79, pp. 953-961.

Boyatzis, R., Goleman, D. and Rhee, K. (2000). Clustering competence in emotional intelligence: Insights from the emotional competence inventory. In Bar-On, R. and Parker, J.D.A. (eds), Handbook of Emotional Intelligence. San Francisco: Jossey-Bass, pp. 343362.

Brotheridge, C.M. and Lee, R.T. (2003). Development and validation of the Emotional Labour Scale. Journal of Occupational and Organizational Psychology, 76, pp. 365-379.

Butler, E.A. and Randall, A.K. (2013a). Emotional coregulation in close relationships. Emotion Review, 5, pp. 202-210.

Butler, E.A. and Randall, A.K. (2013b). Author Reply: Coregulation is a State of a Temporal Interpersonal Emotion System. Emotion Review, 5, pp. 213-214.

Butner, J., Diamond, L.M. and Hicks, A.M. (2007). Attachment style and two forms of affect coregulation between romantic partners. Personal Relationships, 14, pp. 431-455.

Campos, J.J., Walle, E.A., Dahl, A. and Martin, A. (2011). Reconceptualizing emotion regulation. Emotion Review, 3, pp. 26-35.

Carayon, P. and Smith, M.J. (2000). Work organization and ergonomics. Applied Ergonomics, 31, pp. 649-662. 
Chan, D. (1998). Functional relations among constructs in the same content domain at different levels of analysis: A typology of composition models. Journal of Applied Psychology, 83(2), 234-246.

Chapman, A.L., Dixon-Gordon, K.L., Butler, S.M. and Walters, K.N. (2015). Emotional reactivity to social rejection versus a frustration induction among persons with borderline personality features. Personality Disorders: Theory, Research, and Treatment, 6, pp. 8896.

Cole, P.M., Martin, S.E. and Dennis, T.A. (2004). Emotion regulation as a scientific construct: Methodological challenges and directions for child development research. Child Development, 75, pp. 317-333.

Côté, S. (2005). A social interactional model of the effects of emotion regulation. Academy of Management Review, 30, pp. 509-530.

Côté, S. (2014). Emotional intelligence in organizations. Annual Review of Organizational Psychology and Organizational Behavior, 1, pp. 459-488.

Côté, S., Moon, S. and Miners, C.T.H. (2008). Emotion regulation in the workplace. In Ashkanasy, N.M. and Cooper, C.L. (eds), Research Companion to Emotion in Organizations. Cheltenham: Edward Elgar Publishing, pp. 284-300.

Côté, S., Van Kleef, G.A. and Sy, T. (2013). The social effects of emotion regulation in organizations. In Grandey, A.A., Diefendorff, J.M. and Rupp, D.E. (eds), Emotional Labor in the 21st Century: Diverse Perspectives on the Psychology. New York, NY: Routledge, pp. 288-294.

Curşeu, P.L., Boroş, S. and Oerlemans, L.A.G. (2012). Task and relationship conflict in shortterm and long-term groups: The critical role of emotion regulation. International Journal of Conflict Management, 23, pp. 97-107. 
Diamond, L.M. and Hicks, A.M. (2005). Attachment style, current relationship security, and negative emotions: The mediating role of physiological regulation. Journal of Social and Personal Relationships, 22(4), pp. 499-518.

Diefendorff, J.M., Croyle, M.H. and Gosserand, R.H. (2005). The dimensionality and antecedents of emotional labor strategies. Journal of Vocational Behavior, 66, pp. 339-357.

Diefendorff, J.M. and Gosserand, R.H. (2003). Understanding the emotional labor process: A control theory perspective. Journal of Organizational Behavior, 24, pp. 945-959.

Diefendorff, J.M., Erickson, R.J., Grandey, A.A. and Dahling, J.J. (2011). Emotional display rules as work unit norms: A multilevel analysis of emotional labor among nurses. Journal of Occupational Health Psychology, 16, pp. 170-186.

Feldman, R. (2007). Parent-infant synchrony: Biological foundations and developmental outcomes. Current Directions in Psychological Science, 16, pp. 340-345.

Friesen, A.P., Lane, A.M., Devonport, T.J., Sellars, C.N., Stanley, D.N. and Beedie, C.J. (2013). Emotion in sport: Considering interpersonal regulation strategies. International Review of Sport and Exercise Psychology, 6, pp. 139-154.

Geddes, D. and Callister, R.R. (2007). Crossing the line(s): A dual threshold model of anger in organizations. Academy of Management Review, 32, pp. 721-746.

Gracia, E. and Ashkanasy, N.M. (2014). Emotional labor as a dynamic process in service organizations: Development of a multi-perspective, multilevel model. In Ashkanasy, N.M. and Härtel, C.E.J. (eds), Emotions and the Organizational Fabric. United Kingdom: Emerald, pp. 331-365.

Grandey, A.A. (2000). Emotion regulation in the workplace: A new way to conceptualize emotional labor. Journal of Occupational Health Psychology, 5, pp. 95-110. 
Grandey, A.A., Diefendorff, J.M. and Rupp, D.E. (2013). Bringing emotional labor into focus: A review and integration of three research lenses. In Grandey, A. Diefendorff, J. and Rupp, D. (eds), Emotional Labor in the 21st Century: Diverse Perspectives on Emotion Regulation at Work. New York, Routledge, pp. 3-27.

Grandey, A.A. and Gabriel, A.S. (2015). Emotional labor at a crossroads: Where do we go from here? Annual Review of Organizational Psychology and Organizational Behavior, 2, pp. 323-349.

Grandey, A.A., Kern, J.H. and Frone, M.R. (2007). Verbal abuse from outsiders versus insiders: Comparing frequency, impact on emotional exhaustion, and the role of emotional labor. Journal of Occupational Health Psychology, 12, pp. 63-79.

Gratz, K. and Roemer, L. (2004). Multidimensional assessment of emotion regulation and dysregulation: Development, factor structure, and initial validation of the difficulties in emotion regulation scale. Journal of Psychopathology and Behavioral Assessment, 26, pp. 41-54.

Gross, J.J. (1998). The emerging field of emotion regulation: An integrative review. Review of General Psychology, 2, pp. 271-299.

Gross, J.J. (2013a). Conceptualizing emotional labor: An emotion regulation perspective. In Grandey, A., Diefendorff, J. and Rupp, D. (eds), Emotional Labor in the 21st Century: Diverse Perspectives on Emotion Regulation at Work. New York: Routledge, pp. 288-294.

Gross, J.J. (2013b). Emotion regulation: Taking stock and moving forward. Emotion, 13, 359-365.

Gross, J.J. (2015). Emotion regulation: Current status and future prospects. Psychological Inquiry, 26, pp. 1-26.

Gross, J.J. and John, O.P. (2003). Individual differences in two emotion regulation processes: Implications for affect, relationships, and well-being. Journal of Personality and Social Psychology, 85, pp. 348-362. 
Hallam, G.P., Webb, T.L., Sheeran, P., Miles, E., Niven, K., Wilkinson, I.D., Hunter, M.D., Woodruff, P.W., Totterdell, P. and Farrow, T.F. (2014). The neural correlates of regulating another person's emotions: An exploratory fMRI study. Frontiers in Human Neuroscience, 8, pp. 376-388.

Hayward, R.M. and Tuckey, M.R. (2013). Emotional boundary management: A new adaptive approach to emotion regulation at work. In Perrewé, P.L., Rosen, C.C., and Halbesleben, J.R.B (eds), The Role of Emotion and Emotion Regulation in Job Stress and Well Being. United Kingdom: Emerald Group Publishing Limited, pp. 35-74.

Healey, M.P. and Hodgkinson, G.P. (2014). Rethinking the philosophical and theoretical foundations of organizational neuroscience: A critical realist alternative. Human Relations, 67, pp. 765-792.

Hein, G., Silani, G., Preuschoff, K., Batson, C. D. and Singer, T. (2010). Neural responses to ingroup and outgroup members' suffering predict individual differences in costly helping. Neuron, 68, pp. 149-160.

Hobson, N.M., Saunders, B., Al-Khindi, T. and Inzlicht, M. (2014). Emotion down-regulation diminishes cognitive control: A neurophysiological investigation. Emotion, 14, pp. 10141026.

Hochschild, A.R. (1983). The Managed Heart: Commercialization of Human Feeling. Berkeley, CA: University of California Press.

Hofmann, S.G. (2014). Interpersonal emotion regulation model of mood and anxiety disorders. Cognitive Theory and Research, 38, pp. 483-492.

Hulsheger, U.R., Lang, J.W.B., Schewe, A.F. and Zijlstra, F.R.H. (2015). When regulating emotions at work pays off: A diary and intervention student on emotion regulation and customer tips in service jobs. Journal of Applied Psychology, 100(2), 263-277. 
Humphrey, R.H. (2008). The right way to lead with emotional labor. In Humphrey, R.H. (ed), Affect and Emotion: New Directions in Management Theory and Research. Charlotte, NC: Information Age, pp. 1-17.

Humphrey, R.H. (2012). How do leaders use emotional labor? Journal of Organizational Behavior, 33, pp. 740-744.

Humphrey, R.H., Ashforth, B.E. and Diefendorff, J. (2015). The bright side of emotional labor. Journal of Organizational Behavior, 36(6), pp. 749-769.

Humphrey, R.H., Pollack, J.M. and Hawver, T. (2008). Leading with emotional labor. Journal of Managerial Psychology, 23, pp. 151-168.

Jordan, P.J., Ashkanasy, N.M. and Hartel, C.E.J. (2003). The case for emotional intelligence in organizational research. Academy of Management Review, 28, pp. 195-197.

Jordan, P.J., and Lawrence, S. (2009). Emotional intelligence in teams: Development and initial validation of the short version of the Workgroup Emotional Intelligence Profile (WEIP-S). Journal of Management and Organization, 15, pp. 452-470.

Jordan, P.J., Murray, J.P. and Lawrence, S.A. (2009). The application of emotional intelligence in industrial and organizational psychology. In Stough, C., Saklofske, D. and Austin, S. (eds), Advances in Measuring Emotional Intelligence. New York: Springer, pp. 171-190.

Kafetsios, K., Athanasiadou, M. and Dimou, N. (2014a). Leaders' and subordinates' attachment orientation, emotion regulation and affect at work: A multilevel analysis. The Leadership Quarterly, 25, pp. 512-527.

Kafetsios, K., Hantzara, K., Anagnostopoulos, F. and Niakas, D. (2014b). Doctors’ attachment orientations, emotion regulation strategies, and patient satisfaction: A multilevel analysis. Health Communication, 29, pp. 205-214. 
Kafetsios, K., Nezlek, J.B. and Vassilakou, T. (2012). Relationships between leaders' and subordinates' emotion regulation and satisfaction and affect at work. Journal of Social Psychology, 152, pp. 436-457.

Kappas, A. (2011). Emotion and regulation are one! Emotion Review, 3(1), pp. 17-25.

Kenny, D.A. and Albright, L. (1987). Accuracy in interpersonal perception: A social relations analysis. Psychological Bulletin, 102, pp. 390-402.

Klein, K.J. and Kozlowski, S.W. (2000). Multilevel Theory, Research, and Methods in Organizations: Foundations, Extensions, and New Directions. San Francisco: Jossey-Bass.

Kubiak, T., Wiedig-Allison, M., Zgoriecki, S. and Weber, H. (2011). Habitual goals and strategies in anger regulation: Psychometric evaluation of the anger-related reactions and goals inventory (ARGI). Journal of Individual Differences, 32, pp. 1-13.

Lawrence, S.A., Troth, A.C., Jordan, P.J. and Collins, A. (2011). A review of emotion regulation and development of a framework for emotion regulation in the workplace. In Perrewe, P. and Ganster, D. (eds), Research in Occupational Stress and Well-being, Vol. 9. Bingley, West Yorkshire, UK: Emerald Publishing, pp. 197-263.

Little, L.M., Kluemper, D., Nelson, D.L. and Gooty, J. (2012). Development and validation of the Interpersonal Emotion Management Scale. Journal of Occupational and Organizational Psychology, 85, pp. 407-420.

Little, L.M., Kluemper, D., Nelson, D.L. and Ward, A. (2013). More than happy to help? Customer-focused emotion management strategies. Personnel Psychology, 66, pp. 261286.

McAllister, D.J. (1995). Affect-and cognition-based trust as foundations for interpersonal cooperation in organizations. Academy of Management Journal, 38, pp. 24-59.

Mayer, J.D. and Salovey, P. (1995). Emotional intelligence and the construction and regulation of feelings. Applied and Preventive Psychology, 4, pp. 197-208. 
Mayer, J.D. and Salovey, P. (1997). What is emotional intelligence? In Salovey, P. and Sluyter, D.J. (eds), Emotional Development and Emotional Intelligence. New York: Basic Books, pp. 3-31.

Mesmer-Magnus, J.R., DeChurch, L.A. and Wax, A. (2012). Moving emotional labor beyond surface and deep acting: A discordance congruence perspective. Organizational Psychology Review, 2, pp. 6-53.

Mikolajczak, M., Tran, V., Brotheridge, C.M. and Gross, J.M. (2009). Using an emotion regulation framework to predict the outcomes of emotional labor. In Härtel, C.E.J., Ashkanasy, N.M. and Zerbe, W.J. (eds), Research on Emotion in Organizations, Vol. 5. Bingley, UK: Emerald Group Publishing, pp. 245-273.

Morelli, S.A., Rameson, L.T. and Lieberman, M.D. (2014). The neural components of empathy: Predicting daily prosocial behavior. Social Cognitive and Affective Neuroscience, 9, pp. 39-47.

Nelis, D., Quoidbach, J., Hansenne, M. and Mikolajczak, M. (2011). Measuring individual differences in emotion regulation: The emotion regulation profile - revised (ERP-R). Psychologica Belgica, 51, pp. 49-91.

Netzer, L., Van Kleef, G.A. and Tamir, M. (2015). Interpersonal instrumental emotion regulation. Journal of Experimental Social Psychology, 58, pp. 124-135.

Niven, K., Holman, D. and Totterdell, P. (2012a). How to win friendship and trust by influencing people’s feelings: An investigation of interpersonal affect regulation and the quality of relationships. Human Relations, 65, pp. 777-805.

Niven, K., Totterdell, P. and Holman, D. (2009). A classification of controlled interpersonal affect regulation strategies. Emotion, 9, pp. 498-509. 
Niven, K., Totterdell, P., Holman, D. and Headley, T. (2012b). Does regulating others' feelings influence people’s own affective well-being? Journal of Social Psychology, 152, pp. 246260.

Niven, K., Totterdell, P., Stride, C.B. and Holman, D. (2011). Emotion Regulation of Others and Self (EROS): The development and validation of a new individual difference measure. Current Psychology, 30, pp. 53-73.

Parkinson, B. and Totterdell, P. (1999). Classifying affect-regulation strategies. Cognition \& Emotion, 13, pp. 277-303.

Perrone, J. and Vickers, M.H. (2004). Emotions as strategic game in a hostile workplace: An exemplar case study. Employee Responsibilities and Rights Journal, 16, pp. 167-178.

Rameson, L.T., Morelli, S.A. and Lieberman, M.D. (2012). The neural correlates of empathy: Experience, automaticity, and prosocial behavior. Journal of Cognitive Neuroscience, 24, pp. 235-245.

Rimé, B. (2007). Interpersonal emotion regulation. In Gross, J.J. (ed), The Handbook of Emotion Regulation. New York: Guilford Press, pp. 466-485.

Rimé, B. (2009). Emotion elicits the social sharing of emotion: Theory and empirical review. Emotion Review, 1(1), pp. 60-85.

Saxbe, D. and Repetti, R.L. (2010). For better or worse? Coregulation of couples’ cortisol levels and mood states. Journal of Personality and Social Psychology, 98, pp. 92-103.

Sbarra, D.A. and Hazan, C. (2008). Coregulation, dysregulation, self-regulation: An integrative analysis and empirical agenda for understanding adult attachment, separation, loss, and recovery. Personality and Social Psychology Review, 12, pp. 141-167.

Seeley, S.H., Garcia, E. and Mennin, D.S. (2015). Recent advances in laboratory assessment of emotion regulation. Current Opinion in Psychology, 3, pp. 58-63. 
Skinner, E.A., Edge, K., Altman, J. and Sherwood, H. (2003). Searching for the structure of coping: A review and critique of category systems for classifying ways of coping. Psychological Bulletin, 129, pp. 216-269.

Tamir, M. (2011). The maturing field of emotional regulation. Emotion Review, 3(1), pp. 3-7.

Tamir, M., Mitchell, C. and Gross, J. (2008). Hedonic and instrumental motives in anger regulation. Psychological Science, 19, pp. 324-328.

Tett, R.P., Fox, K.E. and Wang, A. (2005). Development and validation of a self-report measure of emotional intelligence as a multidimensional trait domain. Personality and Social Psychology Bulletin, 31, pp. 859-888.

Totenhagen, C.J., Butler, E.A., Curran, M.A. and Serido, J. (2016). The calm after the storm: Relationship length as associated with couples’ daily variability. Journal of Social and Personal Relationships, 33, pp. 768-791.

Troth, A. C., Jordan, P. J., Lawrence, S. A., \& Tse, H. H. (2012). A multilevel model of emotional skills, communication performance, and task performance in teams. Journal of Organizational Behavior, 33, pp. 700-722.

Troxel, W.M. (2013). Comment: Butler and Randall’s “Emotion coregulation in close relationships”. Emotion Review, 5, pp. 211-212.

Webb, T.L., Miles, E. and Sheeran, P. (2012). Dealing with feeling: A meta-analysis of the effectiveness of strategies derived from the process model of emotion regulation. Psychological Bulletin, 138, pp. 775-808.

Williams, M. (2007). Building genuine trust through interpersonal emotion management: A threat regulation model of trust and collaboration across boundaries. Academy of Management Review, 32, pp. 595-621.

Zaki, J., Bolger, N. and Ochsner, K. (2008). Unpacking the informational bases of empathic accuracy. Emotion, 9, pp. 478-487. 
Zaki, J. and Williams, C. W. (2013). Interpersonal emotion regulation. Emotion, 13, pp. 803810. 